\title{
The Role of Customer Complaints Management in Consumers Satisfaction for New Industrial Enterprises of Iran
}

\author{
Mohammad Taleghani (Corresponding author) \\ Department of Business Management \& Accounting \\ Tonekabon branch, Islamic Azad University, Tonekabon, Mazandaran, Iran \\ Tel: +98-911-131-4029Ｅ-mail:M.taleghani454@yahoo.com \\ Mahmood Samadi Largani \\ Department of Business Management \& Accounting \\ Tonekabon branch, Islamic Azad University, Tonekabon, Mazandaran, Iran \\ Tel: +98-911-193-6748Ｅ-mail:m_samadi_largani@yahoo.com \\ Shahram Gilaninia \\ Department of Business Management \& Accounting \\ Invited Professor in Tonekabon branch, Islamic Azad University, Tonekabon, Mazandaran, Iran \\ Tel: +98-911-335-6977_E-mail: gilani_sh45@yahoo.com \\ Seyyed Javad Mousavian \\ Department of Business Management \& Accounting \\ Invited Master in Tonekabon branch, Islamic Azad University, Tonekabon, Mazandaran, Iran \\ Tel: 98-911-335-4617_E-mail:saba_moosaviyan@yahoo.com
}

Received: June 8, 2011 Accepted: July 25, 2011 doi:10.5430/ijba.v2n3p140

\begin{abstract}
In this paper Customer Complaints Management (CCM) as well as the associated key challenges have been studied as essentials for achieving customer retention and loyalty. Some models de nothing the process of CCM have also been demonstrated and discussed and a complaint intensity framework has been presented in which, the joint distribution of complaint intensity and out come satisfaction scores could be conceptualized in four resulting quadrants and each quadrant suggests a different strategy for CCM. For empowering CCM suggestions have been proposed and Return On Complaint Management (ROCM) has been described as a performance indicator for complaint management profitability. Major findings indicate that effective complaints management requires a cultural change in organization's atmosphere, as well as a systematic approach; different levels should be considered in the complaints management; employees participating in teams play an important role in succeeding the complaints handling processes; and CCM empowerment should include strategy, processes, and analysis.
\end{abstract}

Keywords: Customer, Satisfaction, Complaints, Consumer, Industrial Enterprises, Empowerment

\section{Introduction}

Complaints are a natural consequence of any service activity because "Mistakes are an unavoidable feature of all human endearment and thus also of service delivery" (Boshoff, 2007). Service recovery is the process of putting the situation right (Zemke \& Schaaf, 2000) though it has been defined more widely and more proactively as the action of seeking out and dealing with failures in the delivery of service (Johnston, 2005). The term "complaint management" is used to include service recovery and involves the receipt, investigation, settlement and prevention of customer complaints and recovery of the customer. 
Firms normally consider consumer complaints of any kind to be indispensable indicators of unsatisfactory performance. Without consumers' feedback, they will be unaware of their problems and retain their customers (Crie \& Ladwein, 2002). Lau and Ng (2001) found that dissatisfied consumers who complained had a higher level of repurchase intention than those who did not complain (Lau \& Ng, 2001).

However, previous studies have also shown that many unsatisfied consumers prefer to change brands or suppliers and tell friends or families about their bad purchase experience than to voice their dissatisfaction to companies (Day \& Ash, 2007). For these reasons, it is clearly evident that CCM needs serious attention.

Most organizations that face big challenges in customer complaints handling:

- Suffer from a lack of systematic approach to complaints handling.

- Do not recognize the importance of customer complaints at a strategic level.

- Are ill - equipped in terms of systems and processes for logging in complaints, processing them, etc.

- Are not proficient with measurement and in particular in non - financial areas such as customer satisfaction and complaints.

- Have adverse cultures and too much of "blame and reprimand" practices.

- Have not embraced the concept of quality management and its related concepts.

Customer satisfaction is not an absolute scenario, but very much depends on interactions, feedback, praise, and complaints. Complaints have to be looked at in a constructive, positive and professional perspective:

- They are a way of receiving feedback from customers and therefore necessary means for putting into action improvement plans.

- They are a tool for preventing complacency and harnessing internal competencies for optimizing products and services.

- They are a useful way of measuring performance and allocating resources to deal with the deficient areas of the business.

- They are a useful "mirror" for gauging internal performance against competition and best in class organizations.

- They are a useful exercise for getting closer to the customers and understanding them better.

\section{Complaining Reactions}

Consumers have various alternatives to express their dissatisfactions (Singh, 2000). Several typologies have been proposed to differentiate complainers from non - complainers (Crie \& Ladwein, 2002). Generally, four sets of actions can be summarized from the literature.

First, dissatisfied consumers can take no actions following bad buying experiences. Doing nothing or not repurchasing a firm's product or services are legitimate responses to dissatisfaction (Mowen \& Minor, 2008). Singh (2000) classifies consumers engaging in such behavior as "passives" (Stauss, 2004).

Second, consumers can also take some form of private actions. Private actions refer to actions involving only people inside the consumer's group in informal ways. This may include changing the brand Supplier, ceasing to use the product or service, or warning family and friends. Private actions are more likely to be driven by "getting even and punitive aims" (Zeithaml, 2000). This group is classified as "Voicers" (Stauss, 2004).

Third, consumers can take some form of public actions. public actions involve people and organizations outside the consumer's group in more formal ways. These may be seeking redress directly from the seller or manufacturer and taking legal action against the seller of manufacturer.

They may also be registering a complaint with the seller of manufacturer, a public consumer protection agency, or a private consumer organization (Day, 2007). Complainers may also create a new company to provide a better product or service (Day, 2001). The main purpose of these consumer complaints is to "recover economic loss by getting an exchange or a refund and rebuild self - image" (Davidow, 2007). This group is classified as "Irates" (Stauss, 2004).

Finally, consumers may take a variety of different private and public actions. Consumers may blame sellers and manufacturers for their unsatisfactory product or service. They may choose to boycott sellers and manufacturers by ceasing to use their products or services and spread negative information about their products or services. (Zeithaml, 2000). This last group is classified as "activists" (Stauss \& Seidel, 2004). 


\section{Models of CCM}

Johnston (2001) proposed a model, based on an assumption that prime purpose of designing and developing robust and effective CCM systems is to deliver empowered profits by increasing revenues and reducing costs (Figure 1) (Richins, 2003). As it is shown, complaint processes as the core of the model influences customer satisfaction, process improvement, and employee attitude.

In the following, two more models of CCM are demonstrated, which have been used successfully in the Boeing Aircraft and Tanker (Boeing A \& T) and in the National Roads and motorists Association (NRMA).

$<$ Figure 1 about here>

\subsection{Boeing A \& T}

Winners of the Malcolm Baldrige National Quality Award, the Boeing Company Airlift and Tanker Program (A \& T) designs, manufactures and supports aircraft for both passenger and cargo transportation. They serve four major markets and three major customer groups. Their primary customer is the US Air Force. Boeing A \& T use different approaches to handling customer complaints. Amongst the key aspects of Boeing's complaints handling system is proactive management of customer contacts and complaint resolution through joint teams (Figure 2).

$<$ Figure 2 about here $>$

\subsection{National Roads and Motorists Association (NRMA)}

Winners of the Australian Quality Award in 1992, the NRMA was set up to provide services to road users and to promote the interests of motorists. Some of the services provided by NRMA include: emergency road service, insurance, investment advice, finance, technical, legal, touring, and travel amongst others. NRMA manages complaints through different principles and a three level model (Figure 3), which provides a comprehensive and systematic way to deal with complaints.

\section{$<$ Figure 3 about here $>$}

According to the Figure, it is concluded that a CCM system has different levels, both internal and external and it depends on decision making, which in fact could be affected by organizational strategies.

\section{Comprehensive CCM System}

Although important research has been conducted around CCM system, most models are not comprehensive enough. Therefore, a model for CCM system that integrates practice - tested methodologies such as quality function deployment (QFD), problem solving and failure modes and effects analysis (FMEA) was recently developed by Bosch and Enriquez (2005) (Figure 4) (Krapfel, 2005).

They also proposed three important indicators for measuring the system of CCM success as:

(1) Time to respond to a customer complaint, from receiving it to giving an answer to the affected customer;

(2) Percentage of closed cases out of complaints received; and

(3) Evaluation of service level.

\section{$<$ Figure 4 about here $>$}

\section{The Complaint Intensity Outcome Framework}

The complaint intensity outcome framework is presented in Figure 5. Points along the vertical axis indicate customers' mean attribute complaint intensity scores. The complaint intensity score for a given attribute is equal to the frequency of complaints for that attribute weighted by (i.e. multiplied by) the mean degree of importance which individuals who have complained about that attribute attach to such complaints.

As indicated in (Figure 5), the joint distribution of complaint intensity and outcome satisfaction scores is readily conceptualized in four resulting quadrants. Each quadrant suggests a different strategy.

The attributes found in quadrant I require primary attention owing to their high complaint intensity scores and low outcome satisfaction scores. Accordingly, an immediate - focus strategy is suggested.

$<$ Figure 5 about here $>$

\section{CCM Empowerment}

Empowerment is a powerful means of increasing customer satisfaction when resolving customer complaints. For empowerment to be applied successfully, however, it must be promoted within a framework which includes: 
- Encouraging service providers to take a positive and proactive approach to complaints;

- Developing service providers' skills in handling complaints; being explicit about the level of authority employees have in complaint management;

- Providing support and encouragement to employees in taking responsibility; and taking action to overcome the causes of complaints and generating ownership of the improvement opportunities that complaints bring.

\section{Return on complaint Management (RoCM) as a Performance Indicator for Complaint Management} Profitability

Complaint management profitability (CMP) represents the economic efficiency of the processes and instruments of complaint management systems. CMP is calculated by relating the invested capital to the profit of complaint management. The profit of complaint management is calculated by deducting its costs from its benefits. The invested capital equals the costs of CCM activities within period.

However, in order to calculate CMP sufficient data are necessary. Furthermore, it has to be discussed which costs and benefits to include in this calculation, how to measure the costs, and how to express the benefits monetarily.

Regarding the costs of CCM, Various types can be identified in the context of complaint management. These are described in the following (Davidow \& Dacin, 2007):

(1) Personnel costs arise from human resources that are directly concerned with complaint management processes (e.g. staff of a complaint management department).

(2) Administration costs are generated by expenditures for, e. g. office space and office equipment.

(3) Communication costs are all costs that are associated with necessary communication processes to solve the customer's problem (e.g. phone costs or postage).

(4) Response costs are all costs that arise in the context of the problem solution. Here three types of response costs can be differentiated:

Regarding the benefits of complaint management, four distinct types can be identified on the basis of literature analyses and expert interviews (Singh \& Wilkes, 2006):

(1) The information benefit represents the value that is generated by using information from customer complaints to improve products, to enhance efficiency and to reduce failure costs.

(2) The attitude benefit comprehends the positive attitude changes of the customer due to achieved complaint satisfaction.

(3) The repurchase benefit arises when a complaining customer remains with a company instead of switching to a competitor.

(4) Communication benefits describe the oral effect of complaint management. They are generated when complaints are solved and satisfied customers are engaging in positive word - of - mouth, that is, recommending the company and by that supporting the acquisition of new customers.

To calculate CMP it is necessary to operational the four types of benefits and to value them monetarily. The sum of the benefits less the measured costs equals the profit of CCM. To calculate the return on complaint management (RoCM), (Figure 6), which is the key indicator for complaint management profitability; the profit of complaint management is set against the complaint management investments (costs).

$$
<\text { Figure } 6 \text { about here }>
$$

\section{CCM and Customer Retention}

The repurchase benefit of CCM is achieved when previously dissatisfied customers, who otherwise would have migrated, remain loyal to the company as a result of complaint management activities.

There are different approaches to calculate this effect. For example, a calculation on the basis of individual customer data concerning average. The following example is based on average data. The repurchase benefit is basically calculated in a way that the number of customers who remain loyal because of their experience with the CCM is determined. This number is then weighted with a customer's average profitability.

To be able to do this calculation, the following data are necessary:

- The total number of customers (customer base); 
- The number of complainants;

- The share of convinced and satisfied complainants;

- Their loyalty quota; and

- The percentage of complainants whose actual loyalty can be directly traced to complaint handling.

\section{Conclusions}

In this paper, some models and concepts of managing customer complaints were studied and some important suggestions were proposed in order to empower a CCM system. It was found that managers deal with different challenges such as diverse cultural issues in managing CCM systems and employing quality management approaches in such systems. Culture is an important issue which could affect customer satisfaction, complaint processes and employee attitudes, all together result in organizational profitability. Based on the reviewed models it was also emphasized that a CCM system might have different levels, both internal and external, in which different processes are analyzed with respect to organizational strategies. A comprehensive system of CCM was also presented which included different steps. Moreover, team working was addressed as a critical success factor in managing customer complaints. Besides advantages of team working. It seems necessary to provide training to service providers in the skills, attitudes and behaviors to deal positively and empathetically with difficult situations as a key step in encouraging confidence in staff to be empowered. A well - trained and empowered member of staff can help turn a dissatisfied customer into advocate of the organization.

Organizations should emphasize the importance of identifying customer complaint factors and complaint intentions that crucially determine their business success. With respect to those who consider that complaints are worthless and have no gain, management should consider enhancing mutual communication between service personnel and customers.

It is concluded that excellent service is a genuine key for a better future, for both customers and suppliers (Day, 2004). However, this can only be achieved with a profound knowledge of evolving customer needs. A functional CCM system will generate this knowledge, and such system should be implemented in every company regardless of its size, structure or products.

\section{References}

Berry, L.L., Parasuraman. A.(2001). Marketing Services: Competing Through Quality, New York NY: Free Press.

Boshoff, C.R.(2007).An experimental study of service recovery options", International Jonrnal of Service Industry Management, Vol. 8, No. 2, pp. 110 - 130.

Crie, D.,Ladwein, R.(2002). Complaint letters and commitment theory: an empirical approach in mail order selling", Journal of Targeting, Measurement and Analysis for Marketing, Vol . 11 No. 1, pp. 45 - 55.

Davidow, M., Dacin, P.A.(2007).Understanding and influencing consume complaint behavior: improving organizational complaint management, Advances in Consumer Research, Vol. 24, pp. 450 - 456.

Day, R. L.(2004).Modeling choices among alternative responses to dissatisfaction", Advances in Consumer Research, Vol. 11, 2004, pp. 469-471.

Day, R. L., Grabicke, K., Schaetzle, T.,Stanbach, F.(2001).The hidden agenda of consumer complaining", Journal of Retailing, Vol. 57 No. 3, pp. 56 - 106.

Day, R.L.,Ash, S.B.(2007). Consumer response to dissatisfaction with durable products, Advances in Consumer Research, Vol. 6, pp. $438-44$.

Johnston, R.(2001).Linking complaint management to profit", International Journal of Service Industry Management, Vol. 12, No. 1, pp. 60 - 69. doi:10.1108/09564230110382772, http://dx.doi.org/10.1108/09564230110382772

Johnston, R.(2005).Service failure and recovery: impact, attributes and process, Advances in services Marketing and Management: Research and Practice, Vol. 4, PP. 221 - 228.

Krapfel, R.E.(2005).A consumer complaint strategy model: antecedents and outcomes", Advances in Consumer Research, Vol. 12, pp. 346 - 350.

Krishnan, S.,Valle, A. V.(2007).Dissatisfaction attributions and consumer complaint behavior", Advances in Consumer Research, Vol. 6, pp. $445-9$. 
lau, G.T.,Ng, S.(2001).Individual and situational factors influencing negative word of mouth behaviour", Revue Canadienne des Sciences de 1 'Administration, Vol. 18 No. 3, pp. 163 - 178.

Mowen, J. C.,Minor, M.(2008). Consumer Behaviour, 5 th ed., Prentice - Hall, Englewood Cliffs, NJ.

Richins, M.L.(2003).An analysis of consumer interaction styles in the marketplace", Journal of consumer Research, Vol. 10 No. 1 , pp. $73-82$.

Singh, J.(2000).A typology of consumer dissatisfaction response styles", Journal of Retailing, Vol. 66 No.1,2000,pp.57 -99 .

Singh, J.(2008).Consumer complaint intentions and behavior: definitional and taxonomical issues", Journal of Marketing, Vol. 52, January, pp. 93 - 107.

Singh, J.,wilkes, R. E.(2006).When consumers complain: a path analysis of the key antecedents of consumer complaint response estimates", Academy of Marketing Science, Vol. 24 No 4, P. 350. doi:10.1177/0092070396244006, http://dx.doi.org/10.1177/0092070396244006

Stauss, B.,Seidel, W.(2004). Complaint Management - The Heart of CRM, Thomson publishing, Mason, OH.

Zeithaml, V. A., Parasuraman, A.,Berry, L. L.(2000). Delivering Quality Service, Free Press, New York, NY.

Zemke, R.,Schaaf, R.(2001). The service edge: 101 companies that profit from customer care, New York: Penguin.

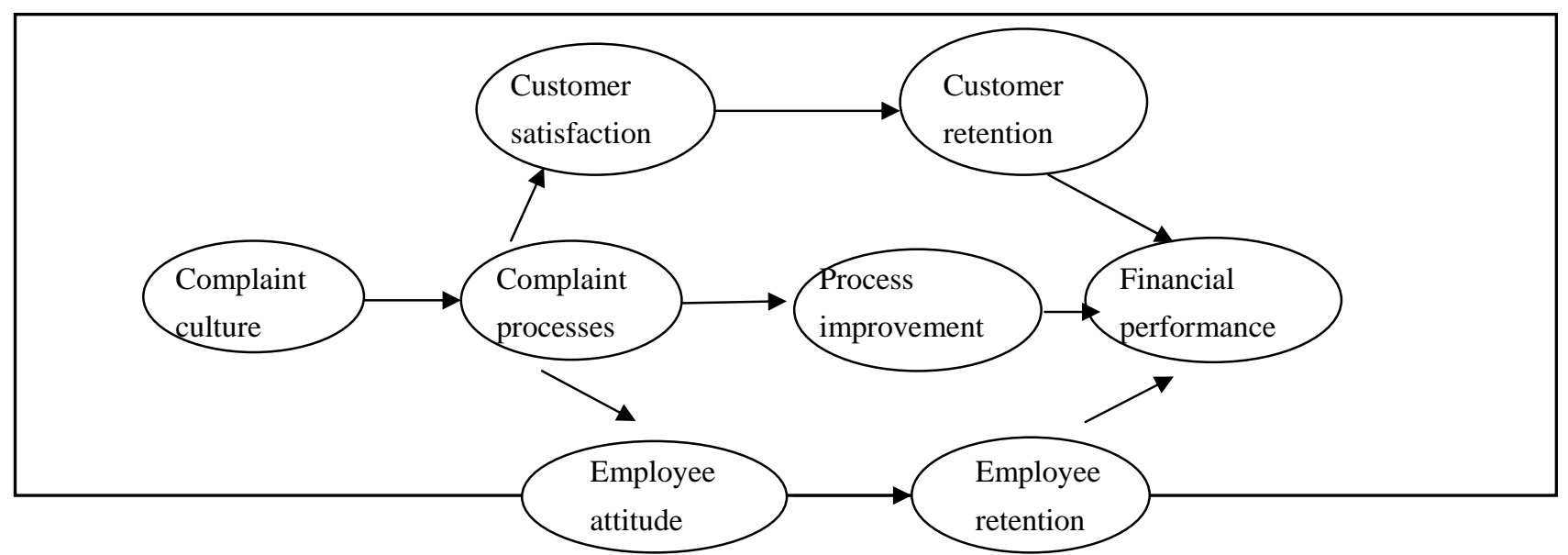

Figure 1. A conceptual model for the relationship between complaint culture (handling), customer satisfaction, and profitability (Johnston, 2005).

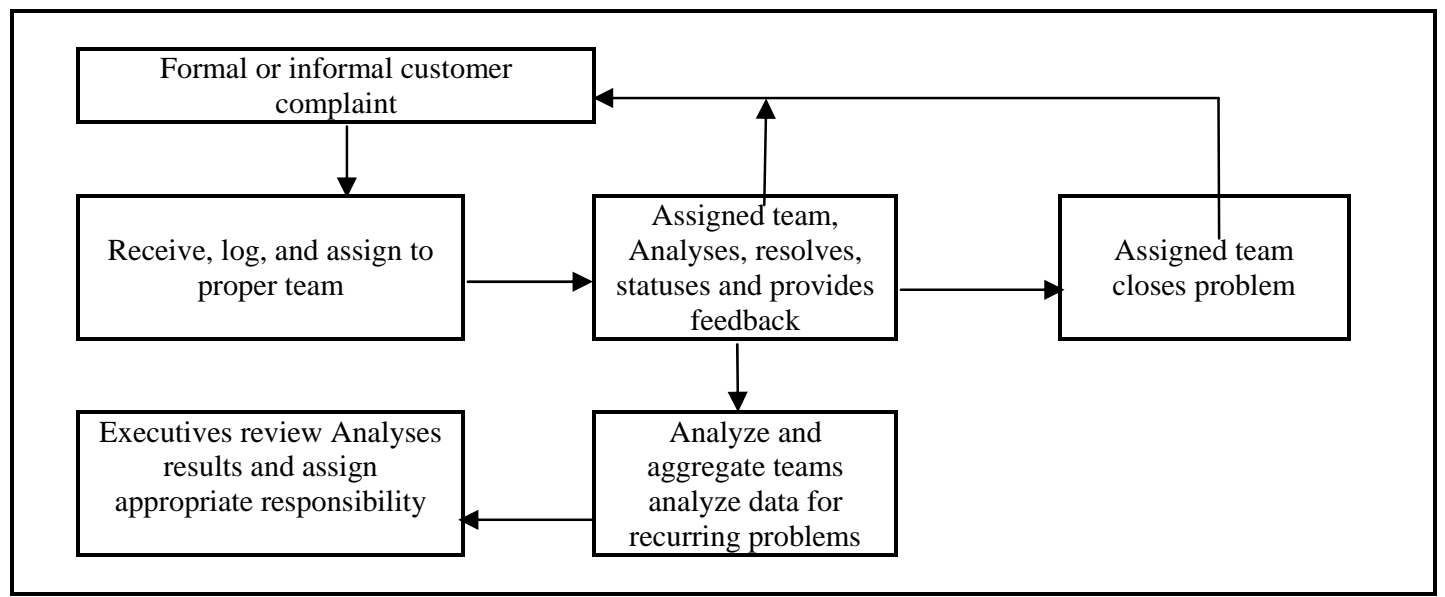

Figure 2. Complaint management model at Boeing A \& T (Singh, 2008). 


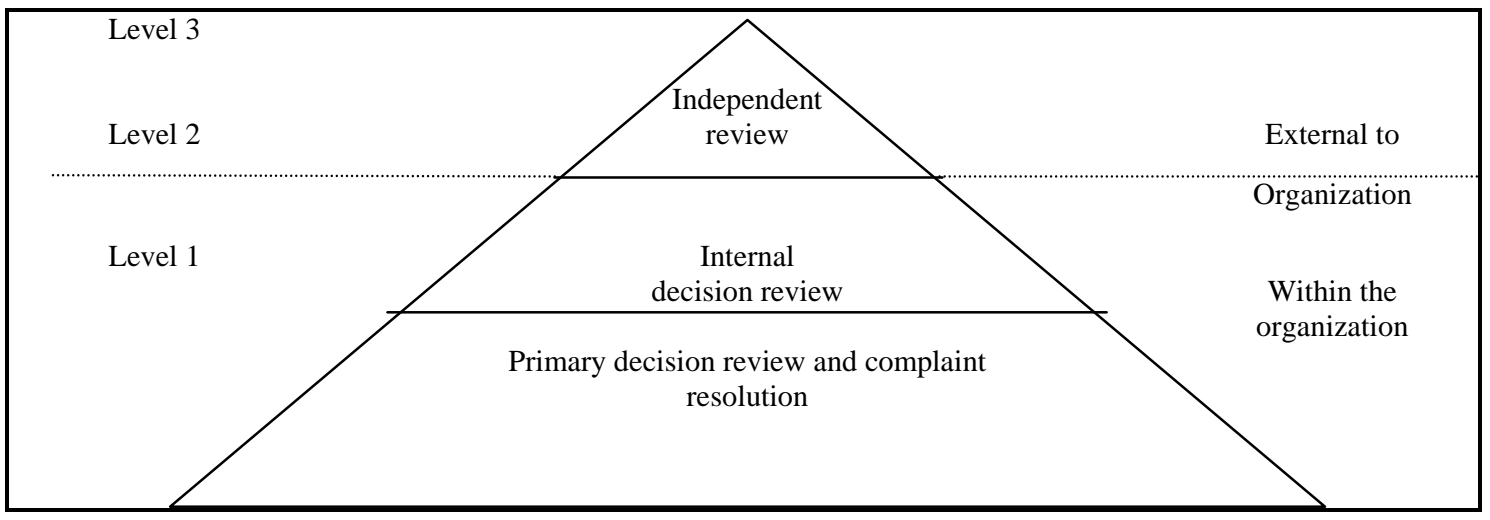

Figure 3. Complaint management model at NRMA (Singh, 2008).

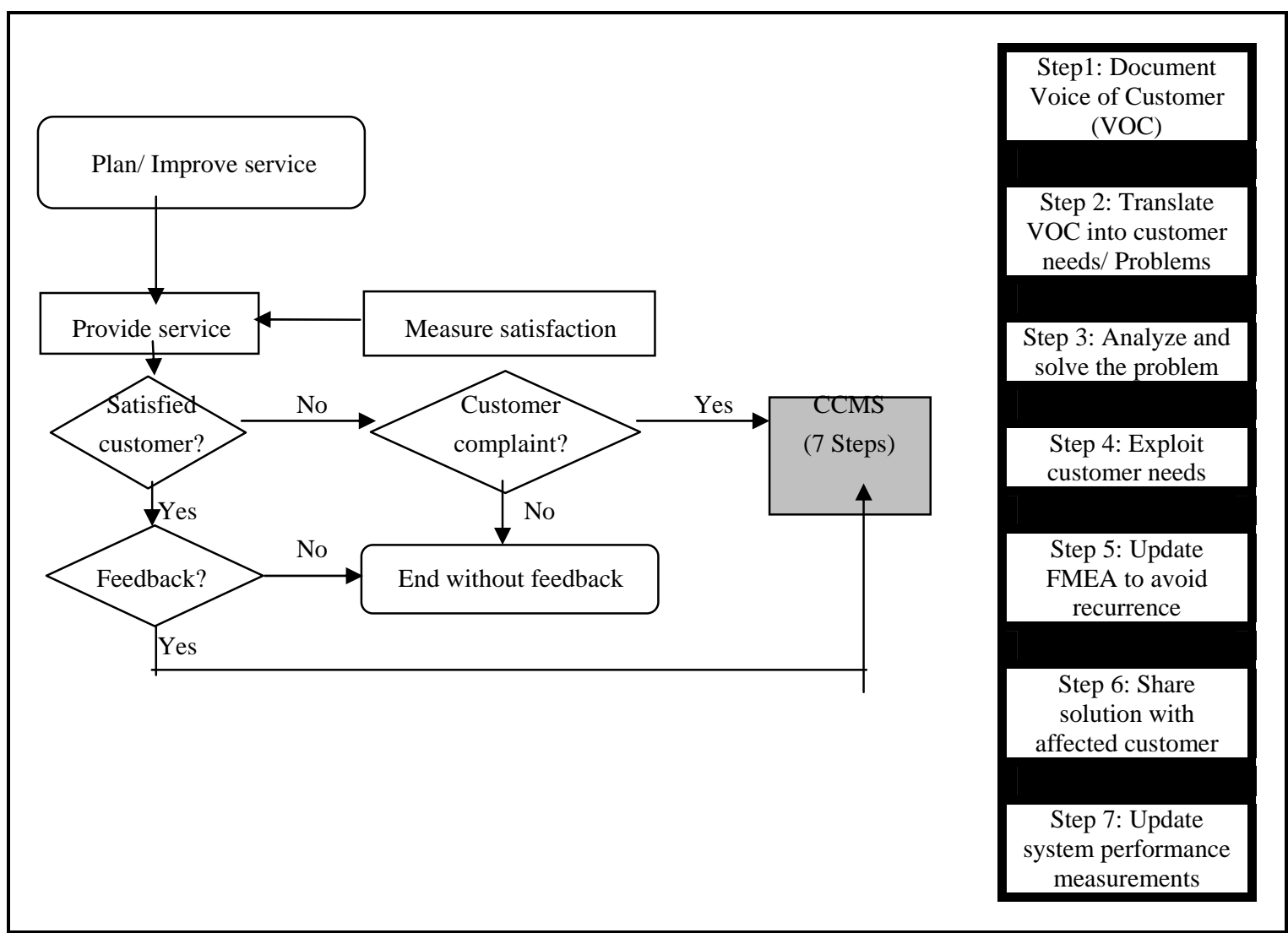

Figure 4. A comprehensive CCM system (Krapfel, 2005). 


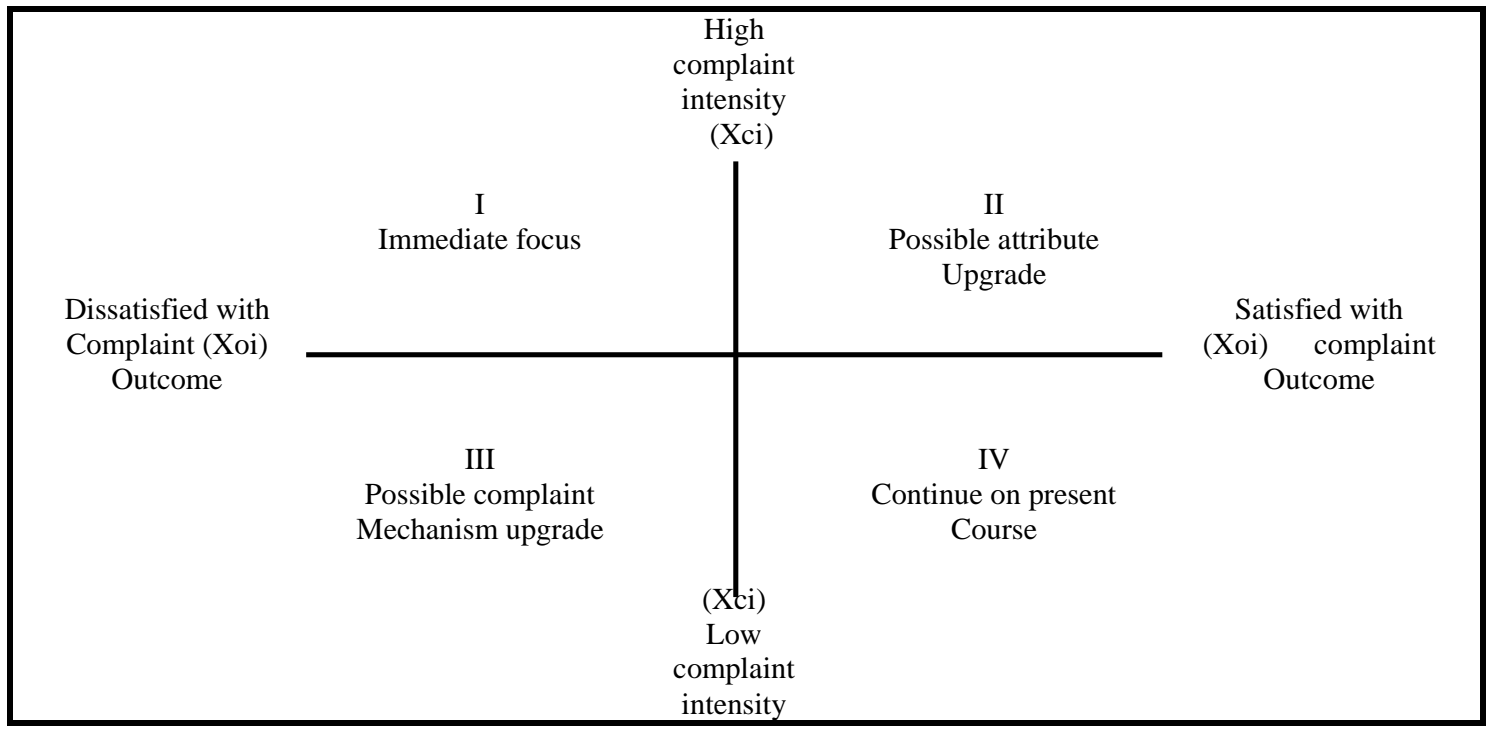

Figure 5. Complaint intensity outcome framework (Krishnan \& Valle, 2007).

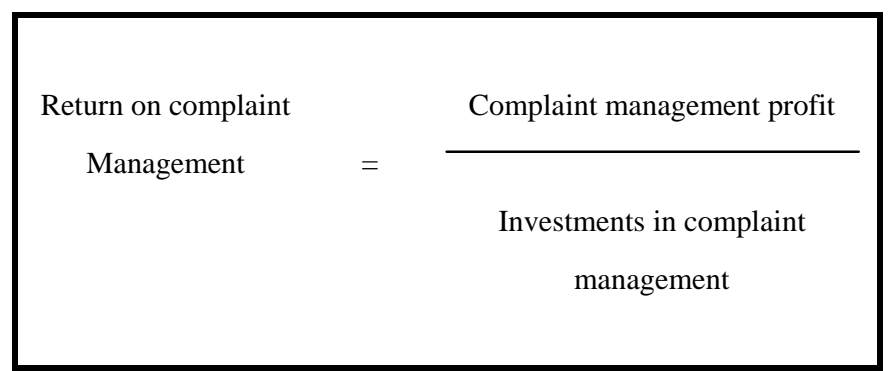

Figure 6. Calculating the return on complaint management (Singh, 2008). 